\title{
Development of road infrastructure safety management system according to updates of EU Directive 96/2008/EC
}

\author{
Fadila Kiso $^{1}$, Ajdin Džananović ${ }^{1}$, Samira Šabanović-Karičić ${ }^{2}$ \\ ${ }^{1}$ University of Sarajevo, Faculty of Traffic and Communication, Zmaja od Bosne 8, Sarajevo 71000, Bosnia and Herzegovina \\ ${ }^{2}$ IPSA Institute, Put života bb, Sarajevo 71000, Bosnia and Herzegovina
}

\begin{abstract}
The traditional approach to the analysis of traffic accidents has mostly involved identifying omissions in vehicles and drivers, which led to the occurrence of a traffic accident. However, more recent EU directives dealing with this area emphasize infrastructure failures that may be the real cause of the accident. This approach refers to preventive action, ie the design of such infrastructure that will, in case of failure of the driver, "forgive" the driver his mistake and prevent the occurrence of a traffic accident or reduce the consequences of a traffic accident. To achieve this, a completely new approach to the problem is needed, i.e. to build, reconstruct and regenerate the road infrastructure according to its real function from the aspect of traffic safety. The realization of these concepts in our area implies primarily the education of all entities that have contact with road infrastructure (designers, managers, auditors, etc.), with emphasis on the fact that savings on the material are significantly less than the savings achieved by reducing the number of accidents, with injured faces and fatalities.
\end{abstract}

Keywords: EU Directive 96/2008/EC, Road Safety, Road Infrastructure, Road Safety Audit

\section{Introduction}

The problem of road safety is a problem that has been current for a long time, from the appearance of a large number of vehicles on the roads until today. Precisely because of the disrupted security in Europe, we had an unacceptable number of dead and seriously injured. To reduce this number, the European Union has taken aggressive steps towards the introduction of documents that seek to define and eliminate most of the causes of traffic accidents. One of these documents of the European Union is Directive 96/2008/EC, which is the subject of this paper, due to its importance and partial neglect in the legislation of many countries.

The paper explains the reason for the introduction of the Directive, as well as the basic subject of consideration. The basic methods derived from the treated Directive are described below, which serve to increase safety on existing roads, but also on roads that have not yet been built. There are four methods here, with a focus on RSI (Road Safety Inspection) and RSA (Road Safety Audit), because they are expected to have the greatest effects of reducing traffic accidents with fatal consequences.
The next part of this paper deals with safety factors in the road system, where they are defined, but the most important segment is the relationship between these factors, and therefore provides insight into their mutual relations in terms of safety and positioning road infrastructure at the top of traffic causes. accident.

Given that the effects of the implementation of the treated Directive were monitored, where the need for certain corrections was identified, in 2019 a proposal for amending the existing Directive was adopted. Therefore, the last part of the paper deals with key amendments to the existing Directive, as well as the need to introduce it into the legislation of many countries, together with a description of the Rulebook on Road Safety Audit and Inspection, which must be adopted to affect traffic safety.

\section{Main points of Directive $96 / 2008$ / EC}

In recent years, in Europe, increasing emphasis is placed on the road as one of the key elements that can significantly change or affect traffic safety conditions. 
Table 1. Growth trend of traffic impact on the number of injured and traffic-related deaths

\begin{tabular}{|c|l|c|l|}
\hline \multicolumn{2}{|c|}{2004} & \multicolumn{2}{c|}{2030} \\
\hline Rank & \multicolumn{1}{|c|}{ Cause of illness / injury } & Rank & \multicolumn{1}{c|}{ Cause of illness / injury } \\
\hline 1 & Heart disease & 1 & Heart disease \\
\hline 2 & Carebrovascular diseases & 2 & Carebrovascular diseases \\
\hline 3 & Infections of the lower respiratory system & 3 & Chronic obstructive pulmonary disease \\
\hline 4 & Chronic obstructive pulmonary disease & 4 & Infections of the lower respiratory system \\
\hline 5 & Digestive diseases & 5 & Injuries in road traffic \\
\hline 6 & HIV / AIDS & 6 & Respiratory cancer \\
\hline 7 & Tuberculosis & 7 & Diabetes \\
\hline 8 & Respiratory cancer & 8 & Hypertensive heart disease \\
\hline 9 & Injuries in road traffic & 9 & Stomach cancer \\
\hline 10 & Premature and low birth weight & 10 & HIV/AIDS \\
\hline
\end{tabular}

The Member States of the European Union has adopted several documents aimed at raising the level of road safety, and these documents include, among others, Directive 2008/96 / EC of the European Parliament and of the Council on road infrastructure safety (19 November 2008).

The reason for the need to introduce this Directive and in general all other documents dealing with the increase of traffic safety can be seen from the following data. The World Health Organization (WHO), which shows the growth trend of traffic as an impact factor on illness and injury, where it can be seen that road traffic was in ninth place in 2004, while it is assumed that traffic in 2030 . jump to fifth place of impact, if nothing is done (Table 1) [1].

On 19 November 2008, the European Parliament and the Council adopted Directive 2008/96 / EC related to road infrastructure safety. It is important to note here that the 2008 Directive applies to the trans-European road network and to roads that are fully or partially funded by the EU, noting that EU members may apply the provisions of the Directive to non-state road networks that are not part of the trans-European road network. European road networks (which is recommended because it enables the achievement of a high level of safety on the complete road network). The main purpose of the Directive is to "produce" tools that will, through their application, maintain traffic safety throughout the life cycle of the road, starting from the road planning process to its maintenance. This implies that the tools derived from this Directive should be used to analyze the road from the aspect of safety in all phases of construction, reconstruction and rehabilitation for new roads, as well as in the phases of maintenance of existing roads.

The key effects of the application of this Directive are as follows [2]:
- Prevention of human and material damage as a consequence of traffic accidents and

- Avoidance of subsequent reconstruction of newly built roads due to non-compliance with safety regulations, and thus avoidance of additional costs.

The application of the Directive requires the establishment and implementation of procedures regarding the following methods for road infrastructure safety management [3]:

1. Road safety Impact Assessment-RIA,

2. Road Safety Audit-RSA,

3. Safety Ranking and Network Safety

Management-NSM and

4. Road Safety Inspection-RSI.

\subsection{Road safety Impact Assessment-RIA}

Road safety Impact Assessment - RIA is conducted for all road infrastructure projects in the feasibility study phase. It contains an assessment of the effects that a new road or a road under reconstruction may have on the level of safety of the infrastructure network. It contains the information necessary for a cost-benefit analysis of different alternatives. The aim is to strategically assess the effects of different alternatives on infrastructure network security.

The main objective of RIA is to prepare a ranking of planned solutions indicating the best variant from the point of view of road safety. The ranking of road safety should take into account both the planned roads and their effect on the road network operation in the impact area [4]. 


\subsection{Road Safety Audit-RSA}

Safety audit in the design and construction phase RSA is an integral part of the planning process and is carried out for all infrastructure road projects in 4 (four) phases:

1. in the conceptual design phase,

2. in the main project phase,

3. immediately before the opening of the infrastructure project and

4. in the phase of initial use of the infrastructure project.

A safety audit (RSA) is an independent, detailed, systematic and technical control of the safety of a road or traffic project, or any other project affecting road users, carried out by an independent qualified auditor or a team of auditors reporting on project accident potential and safety performance, all types of road users [5]. RSA in the post construction context involves a systematic examination of a given section of existing road, to identify and assess hazards arising from the road infrastructure (including geometric design, traffic control devices, road furniture, and the immediate environment) and its usage by public users [6].

Potential problems that may negatively affect road safety are signaled in the planning process by the application of RSA and activities are initiated to solve the identified problems. As RSA aims to act on accidents before they occur and reduce their possible consequences, the application of RSA should be seen as a preventive measure. It is important to point out that the safety of all traffic participants is observed during the implementation of the RSA. RSA differs from standard quality control in that it exclusively and explicitly checks the safety aspect of the project. RSA is a formalized process, within which a written report (RSA report) is submitted to the initiator of the audit (investor) with the listed omissions from the aspect of security and a proposal of measures for elimination of the observed security omissions.

RSA is performed by independent auditors (auditors) who have no previous experience and knowledge related to a given project. Auditors should, as required by the Directive, be fully qualified and trained to perform audits. The process of conducting a security audit can be seen from the previous working diagram (Figure 1) [5].

From this diagram it can be seen that there are three key actors in the RSA implementation process, namely, the Client (road manager), the auditor and the designer. The first phase in the RSA process is that, after the design is completed, Client hires an RSA auditor and provides him with all the necessary documentation. The auditor then performs the audit process, identifies security bugs in the project, and writes an RSA report.

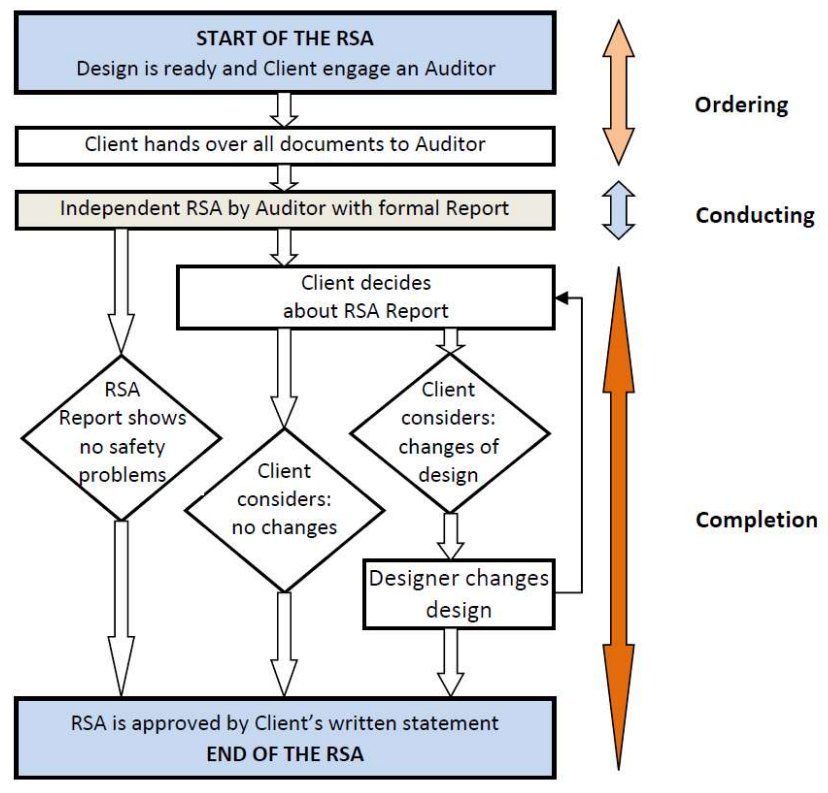

Figure 1. Working diagram of the process for implementing RSA

Client reviews the report and if there are no security bugs, he can start the further process of project implementation, however, if there are security bugs, it is necessary to find an adequate solution. The most effective way of solving is a mutual meeting of all actors in the process, defining variants and finding the best possible solution.

\subsection{Safety Ranking and Network Safety Management-NSM}

Classification and safety management of the existing road network - NSM - parts of the road network with a large number of accidents must be identified, analyzed and classified. Based on the conducted classification, users must be informed about the existence of parts of the network with a high concentration of accidents. The aim is to apply corrective measures to reduce the causes and reduce the cost of accidents based on the classification of parts of the road network with a large number of accidents.

\subsection{Road Safety Inspection-RSI}

The Safety Inspection of the Existing Road Network RSI - is systematic field research, conducted by road safety inspectors for existing roads or road sections to identify hazards or deficiencies that may lead to traffic accidents. The directive stipulates the performance of traffic safety inspections of roads in use, to identify the safety characteristics of the road to prevent accidents. Safety inspections include inspections of the existing road 
network and analysis of possible causes of traffic accidents and the possible impact of road works on traffic flow safety.

Connecting existing levels of road safety and bringing standards to an appropriate consistency is the main objective of RSI. A complementary outcome may also be achieved by RSI: to maintain or restore the original safety level of an existing road. However, it is recognized that most issues related to this secondary outcome should be mainly achieved through regular and more frequent road maintenance inspections [7].

Periodic inspections are carried out by competent authorities. The frequency of inspections should be frequent enough to ensure that an adequate level of road infrastructure safety is maintained. Inspections are initiated or carried out by the body that manages the road network. RSI is one of the preventive methods whose correct application prevents the occurrence of traffic accidents.

The Directive requires the establishment of guidelines for conducting inspections - RSI. Audits are performed, based on the guidelines defined in the checklists. The expert team performing the inspection should be fully professional and trained. At least one team member must have a certificate of competency. Members of the expert team must have relevant experience and education in the field of road design, safety and traffic accident analysis.

Important questions that need to be answered, which are related to RSI, are the following:

1. why implement RSI? - because it has a proactive character and eliminates errors on existing sections that can be the cause of traffic accidents,

2. When to implement RSI? - during the exploitation period, and the frequency varies from country to country,

3. Who implements the RSI - a certified inspection team that is not involved in the planning, construction and maintenance of the road network,

4. Where to implement RSI - on parts of rural, urban networks and highways,

5. How to implement RSI - Implementation according to standardized checklists, and is carried out through the following four steps:

- preparatory actions in the office - include: determining the function of the road, road flow, transit traffic, type and structure of vehicles, the existence of vulnerable participants, capacity, speed limit, etc.,
- field trip - includes: description of the environment, determination of the actual situation (speed, incident situations, the existence of pedestrians and all other elements that may affect the reduction of safety),

- creation of RSI report - the report includes three parts: data on the project, description of the identified shortcomings and proposal of measures to improve the identified shortcomings,

- defect correction and monitoring.

It should be noted here that different rules apply in different countries regarding the certification of inspectors, the manner of conducting the inspection, the scope of the inspection, the type of inspection, the periodicity of the inspection, and checklists.

The advantages or benefits that are realized with RSI can be systematized into the following items:

- identification of potential hazards from the aspect of safety for all traffic participants,

- minimization of the risk of traffic accidents, as well as their consequences and

- minimization of unsustainable losses to health and savings.

\section{Safety factors in the road traffic system}

Analyzing the road traffic system, we come to the basic factors that affect the safety of that system. There are three basic safety factors [8]

1. Human,

2. Vehicle and

3. Road/environment.
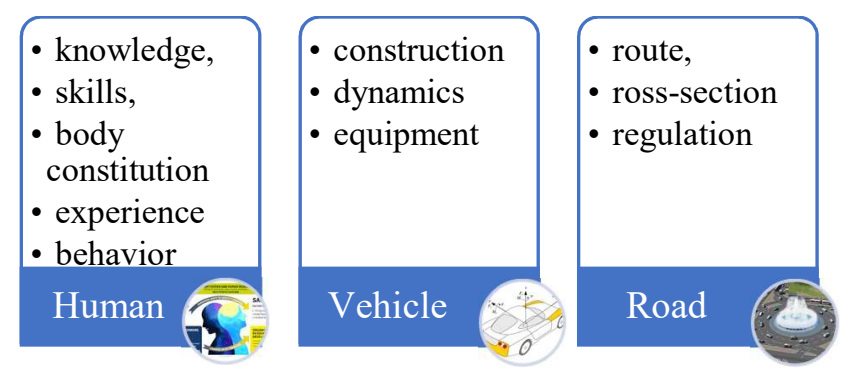

Figure 2. Main characteristics of safety factors

Figure 2 presents basic characteristics of listed safety factors. 
Table 2. Impact of infrastructure in the total number of traffic accidents

\begin{tabular}{|c|c|c|}
\hline \multicolumn{3}{|c|}{ TRAFFIC ACCIDENT STATISTICS IN THE PERIOD 2001-2006 } \\
\hline The reason for the accident & Number & Percentage \\
\hline I And Accidents not caused by infrastructure & 383 & $27 \%$ \\
\hline 1. Animals & 219 & $16 \%$ \\
\hline 2. Time, zones of works & 117 & $8 \%$ \\
\hline 3. Driver's mistakes (alcohol, aggression ...) & 47 & $3 \%$ \\
\hline II Accidents caused by infrastructure & 953 & $68 \%$ \\
\hline 1. Insufficient "6-second axiom" & 451 & $32 \%$ \\
\hline 2. Insufficient "Axiom of transparency" & 228 & $16 \%$ \\
\hline 3. Insufficient "Axiom of logic" & 274 & $20 \%$ \\
\hline III Unexplained Accidents & 64 & $5 \%$ \\
\hline Total & 1400 & $100 \%$ \\
\hline
\end{tabular}

There are mutual relations between these three basic parameters, which define the behavior of one safety factor towards another. The relationship between the human factor and the vehicle factor is observed through humanmachine interfaces. However, this field has already been examined and treated in various documents and works, and it implies "links" between man and vehicle that enable the driver to communicate and control the vehicle. From a safety point of view, this would apply to in-vehicle devices that provide active and passive safety.

The relation between vehicle and road also refers to known and tested natural laws of vehicle movement defined by kinematics and dynamics, where their mutual connection and conditionality is determined by speed, acceleration of gravity, coefficient of adhesion, radius of curves, as safety elements observed from this aspect. The previous two relations are very important, but they are quite specific and defined, but the third relation is not so concretized because it refers exclusively to the human factor. For this reason, in recent times, more and more attention is paid to the human-road relationship, which analyzes human behavior in the function of the road on which it moves.

Applying a new approach to analysis (which takes into account human behavior) more and more attention is paid to the third relation of road system safety, i.e. the relation road-human as an element which due to its unsuitability to the user becomes the majority cause of accidents. It is for this reason that Directive 96/2008 / EC places emphasis on increasing the safety of infrastructure facilities that are in the function of the road system. The road does not have to be the root cause of traffic accidents, but it can help in its occurrence.

According to the European Parliament and the Council of the European Union, road infrastructure management provides significant room for improvement, which should be used to reduce road accidents in the European Union.
To argue this, we will take an in-depth analysis of blackheads conducted in Germany. The survey was conducted in one part of Berlin in the period 2001-2006 and results are summarized in Table 2. This research shows that in Germany, which has a very well-developed road infrastructure, in a period of 5 years, road infrastructure is the cause of traffic accidents in $68 \%$ of cases due to violation of three basic axioms about road design from the aspect of human behavior expectations. It is obvious that in the field of infrastructure there is a lot of free space for improvement from the aspect of security and to achieve that it is necessary to follow world trends (examples of good practice of developed countries) and address shortcomings based on that. This implies that it is sometimes necessary to go beyond traditional standards (which are certainly outdated) and adopt the experiences of developed countries in the field of improving safe road infrastructure.

\section{Analysis of key amendments to EC Directive 96/2008}

Given that the European Commission commissioned an impact assessment of the introduction of Directive 96/2008 / EC in 2015, it was found that those Member States that have been carrying out procedures under the Directive on their national roads for a long time achieve a higher level of road safety than the other Member States. they don't do that.

Due to high traffic congestion on the primary road network of the European Union, a large percentage of fatalities was found in terms of the share of these roads in the overall road network ( $15 \%$ of the road network outside settlements in terms of length represents approximately $39 \%$ of all road fatalities). European Union transport). On the roads of the TEN-T network, which are usually motorways, only $8 \%$ of road deaths occur in the European Union. For this reason, the idea came up to transpose the 
directive to motorways and other primary roads that are not part of the TEN-T network.

According to the safe system approach, deaths and serious injuries in traffic accidents can be largely prevented. Ensuring that accidents do not lead to serious or fatal injuries should be a shared responsibility at all levels. In particular, well-designed and properly maintained roads should reduce the likelihood of accidents, while "forgiving" roads (roads that are intelligently designed to ensure that driving errors do not lead directly to serious consequences) should reduce the severity of accidents.

Sections of the road network located near the road tunnels of the trans-European road network covered by Directive (EU) 2004/54 / EC of the European Parliament and the Council have a particularly high risk of accidents. Therefore, joint safety inspections should be introduced on those road sections involving representatives of road authorities and tunnel authorities to improve the safety of the road network as a whole.

In 2016, unprotected road users accounted for $46 \%$ of road deaths in the European Union. Ensuring that the interests of these actors are taken into account in all road infrastructure safety management procedures should therefore improve their road safety. Also, the European Commission is disappointed that the Directive did not provide an incentive to expand the exchange of good practices between the Member States, which was one of the basic ideas of the implementation of the Directive. Taking into account this analysis of the application of the existing Directive and the effects obtained with it, in February 2019, the latest version of the proposal to amend Directive 96/2008 / EC was submitted and adopted. The most significant changes in the proposal for a Directive are the following [9]:

- Article 2 (definitions) changes the term "Safety inspection" as "Periodic Road Safety Inspection" - means a targeted field inspection of an existing road or road section to identify hazardous conditions, errors, or deficiencies that increase the risk of accidents. and injury)

- In Article 2, the definition of "Unprotected road user" is added (Unprotected road user - means non-motorized road users, including, in particular, cyclists and pedestrians, but also drivers of motor vehicles on two wheels),

- Major changes have been made to Article 5, the most significant of which is in paragraph 1 (the Member States must ensure that road networkwide road assessments are carried out on the complete road network in use and covered by this Directive. Network-wide road assessments the
Member States must ensure that the first assessment is carried out by 2025 at the latest. adequate levels of security would be ensured, but in any case, implemented at least every five years),

- In Article 6, paragraph 6a (Further action in proceedings for used roads), paragraph $6 \mathrm{~b}$ (Protection of unprotected road users), 6.c (Road signs and traffic signs), 6.d is added. Information and transparency) and 6.e (Voluntary reporting),

- Additional points ( $\mathrm{n}$ and $\mathrm{h}$ ) are added in Annex II - during the first safety, the contents for unprotected road users must be taken into account,

- Annex IIa is added, which lists the elements of road safety, because the emphasis is on improving the safety of existing roads, and the verification of the elements is done through 8 PIARC categories,

- Annex IV is supplemented through the mandatory introduction of GNSS coordinates (when determining the location).

Note that, only the most significant changes are listed because we believe that they are crucial to creating the legal legislation of middle-developed countries. To comply with the requirements of the Directive, it is necessary to adopt an adequate Ordinance which should define, inter alia, the following items:

- conditions for performing road safety audits and inspections,

- scope of audit and inspection,

- manner of performing audit and inspection,

- period of performing audit and inspection,

- method of certification of inspectors and auditors,

- qualifications and number of professional staff for performing audits and inspections,

- defining checklists for audit and inspection,

- defining the form of the final report after the audit and inspection,

- auditing and inspection budgeting.

\section{Conclusion}

Analyzing the current conditions in Europe, average costs for one traffic-related death in traffic accident is over 2000000 EUR. Starting from this fact, it can be noted that it is profitable to invest in the development of procedures for detecting security shortcomings, which can be the cause of human fatalities, and then correction 
of the observed shortcomings. This was the idea of the European Union to bring the documents into practice and develop methods that would prevent them from affecting and thus not affect traffic accidents, and in the event of an accident there will be fewer consequences ("better prevention than treatment"). Directive 96/2008 / EC has been applied fairly well in developed European countries, but it has not yet fled to be used in poorly developed country. In order to benefit from this Directive, it is necessary to first of all introduce the Directive into state legal regulation. The next step is to educate staff for the implementation of auditing and road safety inspections including all stakeholders such as road managers, designers, university institutions, authorities, etc..

\section{References}

[1] L. Barelli, G. Bidini, G. Cinti, H. H. Zhang, and et al., "Global status report on road safety 2018," World Health Organization, 2018. [Online]. Available: https://www.who.int/publications/i/item/9789241565684

[2] K. Karkin, "Directive on road safety No. 2008/96 and its implementation in Bosnia and Herzegovina," in International conference on road infrastructure safety management, 2010, pp. 51-53.

[3] Z. Kenjić, "Framework conditions for implementation of the European," in International conference on road infrastructure safety management, 2010, pp. 42-50.

[4] W. Kustra, K. Jamroz, and M. Budzynski, "Safety PL- A Support Tool for Road Safety Impact Assessment, Transportation Research Procedia", vol. 14, pp. 34563465, April 2016.

[5] H. J. Vollpracht, L. Pfeiffer, R. Baumann, A. Ross, and et al., "Road safety audit process" in Practical Guide for Road Safety Auditors and Inspectors, Belgrade, Serbia: AMSS, 2018, pp. 6-7.

[6] E. S. M. M. Zahran, S. J. Tan, E. H. A. Tan, N. A. A. B. Mohamad 'Asri Putra, Y. H. Yap, and E. K. Abdul Rahman, "Spatial analysis of road traffic accident hotspots: evaluation and validation of recent approaches using road safety audit," Journal od Transportation Safety Security, vol. 13 , no. 6 , pp. 575-604, Sep. 2021.

[7] C. Roque, J. Lourenço Cardoso, T. Connell, G. Schermers, and R. Weber, "Topic analysis of Road safety inspections using latent dirichlet allocation: A case study of roadside safety in Irish main roads," Accident Analysis and Prevention, vol. 131, pp. 336-349, April 2019.

[8] O. H. Kwon, W. Rhee, and Y. Yoon, "Application of classification algorithms for analysis of road safety risk factor dependencies," Accident Analysis and Prevention, vol. 75, pp. 1-15, Nov. 2015.

[9] European Commission, "Proposal for a Directive of the European Parliament and of the Council amending Directive 2008/96/EC on road infrastructure safety management," Brussels, 2018. 